Eurasian Journal of Soil Science

Journal homepage : http://ejss.fesss.org

\title{
Effect of polyvinyl alcohol on the physico-chemical properties of soil and soil-amino acid interaction
}

\section{Jamal Ahmad Khan a, Shagufta Jabin b, Priti Gupta c,*}

a Department of Applied Chemistry, Faculty of Engineering \& Technology, AMU, Aligarh, India

b Department of Chemistry, Faculty of Engineering, Manav Rachna Institute of Research \& Studies, Faridabad, India ${ }^{c}$ Department of Chemistry, Faculty of Applied Science, Manav Rachna University, Faridabad, India

\section{Article Info}

Received : 18.06 .2019

Accepted : 30.09.2020

Available online : 05.10 .2020

\section{Author(s)}

J.A. Khan

S. Jabin

P. Gupta*

* Corresponding author

\begin{abstract}
Thin layer chromatography (TLC) is considered as an efficient analytical technique used for the monitoring and identification of the adsorption behaviour of different amino acids through soil as a stationary phase amended with polyvinyl acetate at different concentration. The study gives complete idea about the mobility of four different uncharged amino acids namely glycine, alanine, tryptophan and glutamine in terms of retention factor by thin layer chromatography. Among four amino acids, highest mobility was found in case of glycine. The order of mobility was found to be in order of glycine > alanine $>$ tryptophan $>$ glutamine in which distilled water has been used as a mobile phase. It has been observed from the results that $\mathrm{pH}$ and electrical conductivity also influence mobility of amino acids. The influence of activation temperature and particle size of soil on the mobility of amino acids was also studied.
\end{abstract}

Keywords: Soil, amino acids, electrical conductivity, pH, poly-vinyl acetate, retention factor, TLC.

(C) 2021 Federation of Eurasian Soil Science Societies. All rights reserved

\section{Introduction}

Soil thin layer chromatography is one of the most versatile techniques used for the separation and identification of some of the important organic and inorganic compounds through soil bed (Khan et al., $2000 a, b)$. Few researchers have studied mobility of amino acids on soil bed by used soil chromatographic technique (Swarnakumari et al., 2019).

In soil, nitrogen occurs in organic and inorganic forms. Most surface soils account for greater than $95 \%$ of the total nitrogen (Ros et al., 2011). It has been found from literature that about $40 \%$ of total nitrogen exists in soils in the form of amino acids. These amino acids are divided into three different categories.

(i) They are present in dissolved form in the soil solution. They are considered as free amino acids (FAA) and freely available for plants (Jones et al., 2005a).

(ii) They are present in the form of exchangeable amino acids which are attached to charged surfaces on soil organic matter and clay particles of soil (Jones et al., 2005a).

(iii) The large fractions of amino acids are generally present in the form of proteinaceous amino acids which are present in proteins and peptides. They are called Bound amino acids (BAA) (Schulten and Schnitzer, 1997).

Bound amino acids (BAA) are mostly available indirectly to the plants and considered as reservoir. However, the concentration of FAA in soil is found to be in the range of 0-158 $\mu \mathrm{M}$ (Jones et al., 2005b).

In the present study, interaction of soil with amino acid was done by soil thin layer chromatographic technique. It was done with four different amino acids viz; glycine, alanine, glutamine and tryptophan. All

https://doi.org/10.18393/ejss.805214

http://ejss.fesss.org/10.18393/ejss.805214 
four amino acids are uncharged in nature. The different properties of glycine, alanine, glutamine and tryptophan have been tabulated in Table 1.

Table 1. Properties of glycine, alanine, glutamine and trytophan

\begin{tabular}{|c|c|c|c|c|c|}
\hline $\begin{array}{l}\text { Amino } \\
\text { Acids }\end{array}$ & $\begin{array}{l}\text { Molecular } \\
\text { Masses } \\
\text { (gm per mol) }\end{array}$ & Structures & $\begin{array}{l}\text { Solubility } \\
\text { (in gm per } 100 \mathrm{ml} \\
\text { water at } 25^{\circ} \mathrm{C} \text { ) }\end{array}$ & Nature & Acidity (pKa) \\
\hline Glycine & 75.07 & & 24.99 & $\begin{array}{l}\text { Non-Polar, } \\
\text { uncharged }\end{array}$ & $\begin{array}{l}2.34 \text { (carboxyl), } 9.6 \\
\text { (amino) }\end{array}$ \\
\hline Alanine & 89.09 & & 16.7 & $\begin{array}{l}\text { Non-Polar, } \\
\text { uncharged }\end{array}$ & $\begin{array}{l}2.34 \text { (carboxyl) } 9.87 \\
\text { (amino) }\end{array}$ \\
\hline Glutamine & 146.14 & & 4.13 & $\begin{array}{l}\text { Polar but } \\
\text { uncharged }\end{array}$ & $\begin{array}{l}2.2 \text { (carboxyl), } 9.1 \\
\text { (amino) }\end{array}$ \\
\hline Tryptophan & 204.23 & & 11.4 & $\begin{array}{l}\text { Non-Polar, } \\
\text { uncharged }\end{array}$ & $\begin{array}{l}2.38 \text { (carboxyl), } 9.39 \\
\text { (amino) }\end{array}$ \\
\hline
\end{tabular}

Many organic waste chemicals like organic acids, alcohols, dyes, polymers, etc., enter into the soil which can affect soil properties and composition of many useful compounds and micro-organisms present in soil (Tian et al., 2020). Organic acids, alcohols, dyes and polymers come in the soil from different sources which may include plant roots and microorganisms. These compounds affect the soil quality and soil structure and part of wastewater containing dyes, polymers and alcohol can also leach in underlying ground water and affects its soil quality.

Polyvinyl alcohol (PVA) is an environment-friendly, water soluble and degradable polymer. PVA is also called as soil stabilizer (Liu et al., 2017). Its main composition is acetic-ethylene-ester polymer (Ding et al., 2002). It contains $\mathrm{OOCCH}_{3}$ functional groups in large amount. PVA has a solid content of $41 \%$, a pH of around 7, a specific gravity of $1.05 \mathrm{gm}$ per $\mathrm{cm}^{3}$ and a viscosity of $400 \mathrm{mPas}$ (Aslam et al., 2018). PVA can form a viscous and elastic membrane on soil surface. The study is focused on the effect of PVA on the physicochemical properties of soils and amino acids-soil interaction. Soil thin layer chromatography has been studied successfully by soil scientists for determination of amino acids mobility through soil bed (Khan and Moheman, 2005, Tian and Xie, 2008, Mohammad et al., 2012). Clay composition of the soil has a direct relation to mobility of amino acids in soil (Khan et al., 2012). Perhaps soil TLC could not been be used till date in the identification and separation of amino acids with soil amended with poly vinyl acetate.

\section{Material and Methods}

Four amino acids glycine, alanine, glutamine and tryptophan and ninhydrine have been purchased from CDH (India) and $0.01 \mathrm{M}$ amino acid solution was prepared in distilled water. Poly vinyl acetate has been purchased from Sigma Aldrich.

\section{Determination of physico-chemical properties of soil}

For the investigation, soil sample was collected from Aligarh district (27.89 $\left.\mathrm{N}, 78.08^{\circ} \mathrm{E}\right)$, state Uttar Pradesh, India. The sample was first dried at room temperature in tray of non-rusting material and then it was crushed in a mortar. Further it was passed through $150 \mu \mathrm{l}$ size sieve so that uniformity in particle size can be maintained. Physico-chemical properties of soil were determined.

- The mechanical composition of soil was analyzed by standard method of "International pipette" (Mitchell and Kenichi, 2005). The pH of soil was measured by pH meter (Elico model L1-10T).

- The soil electrical conductivity was calculated by conductivity cell by measuring the electrical cell resistance of 1:5 soil suspensions (Hanna HI 8314, USA).

- The moisture content and moisture percentage (both wet and dry) in soil has been calculated and the result obtained for the moisture content is recorded in Table 2.

- The organic matter of the soil sample was measured by Walkley and Black method (Souza et al., 2016).

- Cation exchange capacity was estimated by the Jackson method (Aprile and Lorandi, 2012). PhysicoChemical properties of soil are tabulated in table 2 . 
Table 2. Pyhsico-chemical properties of stationary soil phase

\begin{tabular}{|c|c|c|}
\hline \multicolumn{2}{|c|}{ Parameters } & Values \\
\hline \multicolumn{3}{|c|}{ Mechanical composition (\%) } \\
\hline (i) & Sand & 71.08 \\
\hline (ii) & Silt & 19.72 \\
\hline (iii) & Clay & 09.20 \\
\hline \multicolumn{2}{|c|}{ pH (1:5, soil:water) } & 6.73 \\
\hline \multirow{2}{*}{\multicolumn{3}{|c|}{$\begin{array}{l}\text { Electrical conductivity }\left(\mathrm{dSm}^{-1}\right) \\
\text { Determination of moisture content }\end{array}$}} \\
\hline & & \\
\hline (i) & Moisture content & 10.50 \\
\hline (ii) & Moisture percentage (wet soil basis) & 21.00 \\
\hline (iii) & Moisture percentage (oven-dry basis) & 26.58 \\
\hline \multicolumn{3}{|c|}{ Exchangable cations $\left(\mathrm{Cmol}\left(\mathrm{p}^{+}\right) \mathrm{Kg}^{-1}\right.$ soil $)$} \\
\hline (i) & $\mathrm{Na}^{+}$ & 0.52 \\
\hline (ii) & $\mathrm{K}^{+}$ & 0.82 \\
\hline (iii) & $\mathrm{Ca}^{2+}$ & 5.50 \\
\hline (iv) & $\mathrm{Mg}^{2+}$ & 1.50 \\
\hline
\end{tabular}

\section{Preparation of glass plates}

To determine the $\mathrm{R}_{\mathrm{f}}$ values of four amino acids, the soil sample were dried at room temperature, and then crushed in a mortar. It was then passed through a $150 \mu \mathrm{l}$ size sieve so that uniform particle size can be obtained. The soil slurry was prepared in distilled water with different concentration of PVA. The resultant consistent slurry was spread onto glass plate of $200 \times 35 \times 0.25 \mathrm{~mm}$ size. The coated plates were air dried and then it was kept in an air-tight chamber further used.

\section{Loading of amino acids and development of plates}

A $15 \mu \mathrm{l}$ amount of the $0.01 \mathrm{M}$ amino acid solution was smeared on the base line of soil coated TLC plate using micropipette. Micropipette was obtained from Abdos Labtech, India. Glass plates were developed into glass chamber by using distilled water as a developer up to a distance of $10 \mathrm{~cm}$ as shown by the upper line on TLC plates. Glass chamber was obtained in the laboratory from Sisco, India.

\section{Detection of chromatograms}

The developed plates were air dried at room temperature and amino acids were marked by spraying $0.2 \%$ alcoholic solution of ninhydrin (weight divided by volume). All of them were kept in an oven (Labline equipment) at temperature range of $70-80^{\circ} \mathrm{C}$ for $20 \mathrm{~min}$ till appearance of pink coloured spots. Further, $\mathrm{R}_{\mathrm{f}}$ values of amino acids was determined after the spots were stable for several days.

\section{Results and Discussion}

The separation and identification of amino acids are important because of their increasing pharmaceutical, industrial, pesticidal and toxicological applications. Figure 1 to Figure 5 illustrate $\mathrm{R}_{\mathrm{f}}$ values of different amino acids such as glycine, alanine, glutamine and tryptophan through stationary soil phase with and without PVA at different concentration. The $\mathrm{R}_{\mathrm{f}}$ values of glycine $>$ alanine $>$ glutamine $>$ tryptophan through pure soil as a stationary phase (without PVA) and it is found to be $0.72,0.70,0.69$ and 0.66 respectively (as shown in Figure 1). The same trend is observed in soil amended with different concentration of PVA. The trend is negatively correlated with the size and molecular weight of different amino acids. The molecular weight are $75.07 \mathrm{gm}$ per mol, $89.09 \mathrm{gm}$ per mol, $146.14 \mathrm{gm}$ per mol and $204.22 \mathrm{gm}$ per mol for glycine, alanine. tryptophan and glutamin respectively. The size of amino acid molecules is found to be affecting their diffusion rate through soil TLC. The mobility decreases with increasing order of size and molecular masses of amino acids.

The $\mathrm{R}_{\mathrm{f}}$ values of amino acids decreases with increasing PVA concentration in soil. The impact of individual parameters is highly dependent on the characteristics of different amino acids. The mobility of amino acids is found to decrease with higher dosages of PVA in soil bed. It may be due to high adsorption capacity of PVA for amino acids. The data proves that highest mobility was observed in case of glycine in pure soil as well as in soil amended with PVA. At the different concentration of PVA viz; 0.0001, 0.001, 0.01 and $0.1(0.001 \%$, $0.1 \%, 1 \%, 10 \%$ respectively) amended with soil, $\mathrm{R}_{\mathrm{f}}$ values of glycine were found to be $0.79,0.77,0.76$ and 0.74 respectively. However, in case of alanine, tryptophan and glutamine, the same trend was observed with same concentration of PVA amended with soil. However, minimum $\mathrm{R}_{\mathrm{f}}$ values were obtained in case of glutamine. The reduction in $\mathrm{R}_{\mathrm{f}}$ values may be reported due to high adsorption capacity of the soil for 
glutamine as a result of the increased surface area of the particles. As the process of adsorption progress, equilibrium exists between adsorbate and adsorbent. The adsorbate and adsorbent combine together by the phenomenon of chemisorption. However, it is interesting to note that $\mathrm{R}_{\mathrm{f}}$ values of all amino acids were found to be minimum in pure soil as stationary phase as compared to soil amended with PVA. It may be because of strong electrostatic force of attraction between pure soil and different amino acids. Pure soil provides a surface on which amino acids can be adsorbed easily due to its highly porous nature. On the other hand, soil amended with PVA is having poor porosity due to the already adsorbed PVA on the surface of soil.

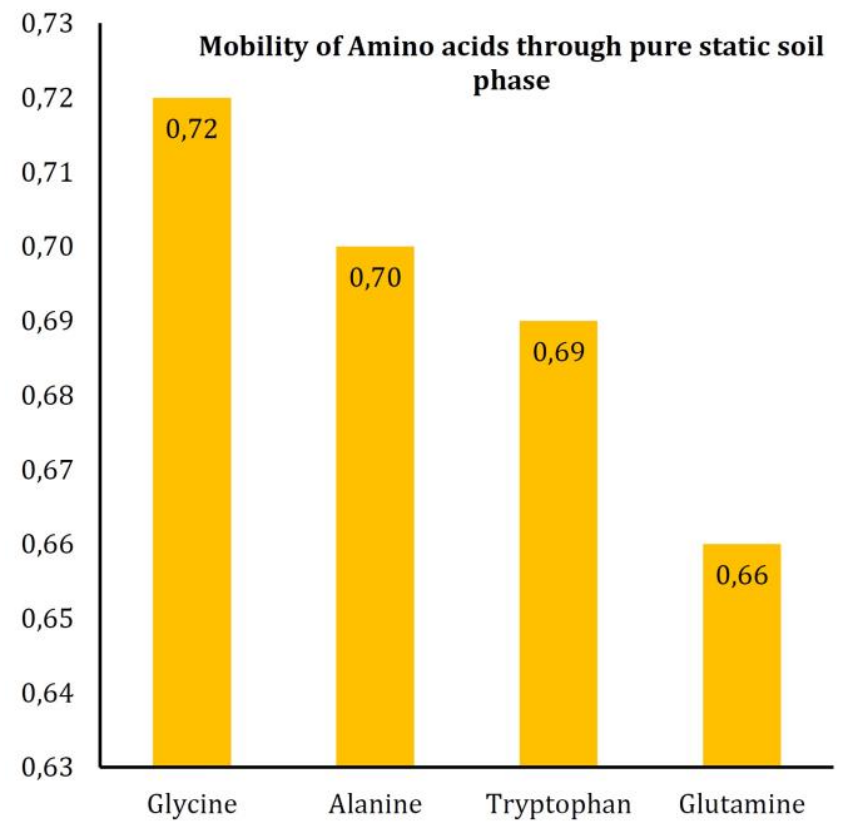

Figure 1. Mobility of amino acids through statinary soil phase

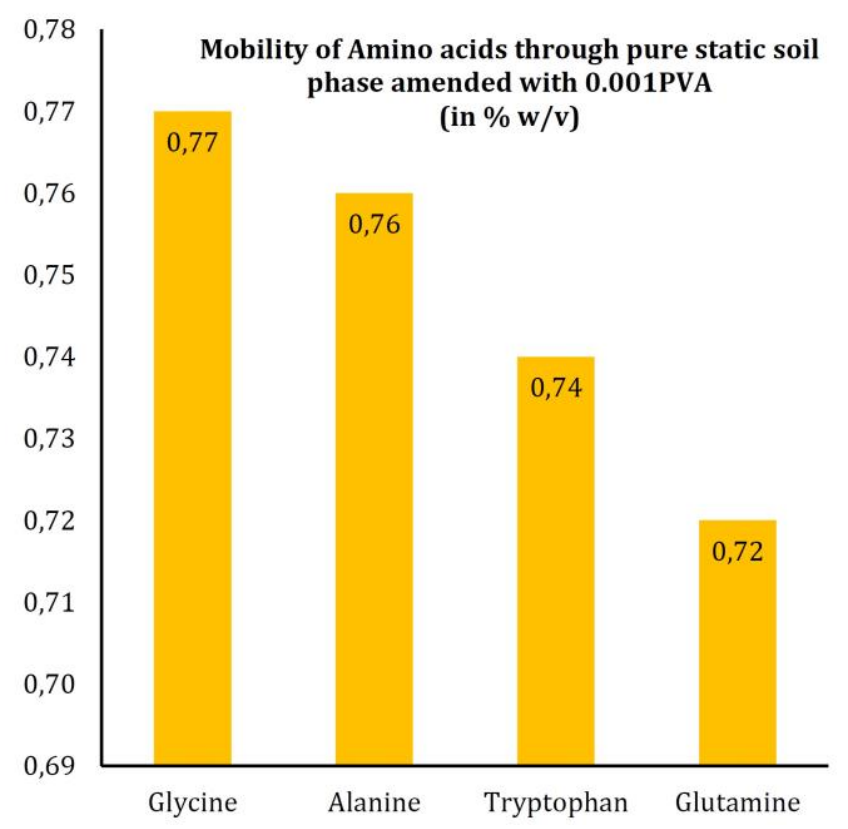

Figure 3. Mobility of amino acids through stationary soil phase amended with 0.001PVA (in \% weight divided by volume)

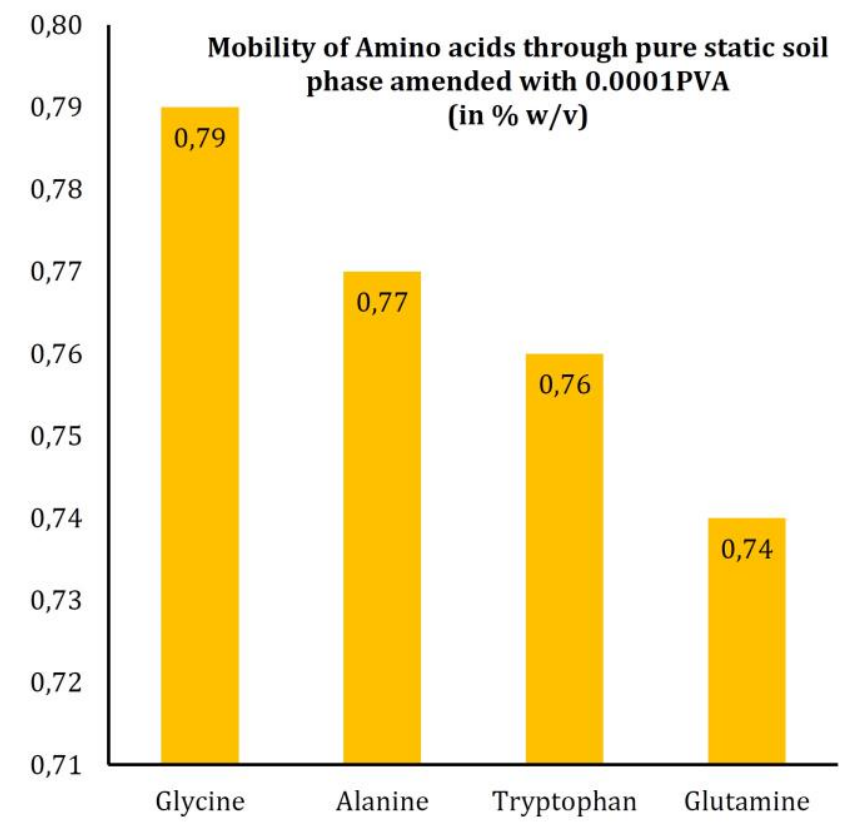

Figure 2. Mobility of amino acids through stationay soil phase amended with 0.0001PVA (in \% weight divided by volume)

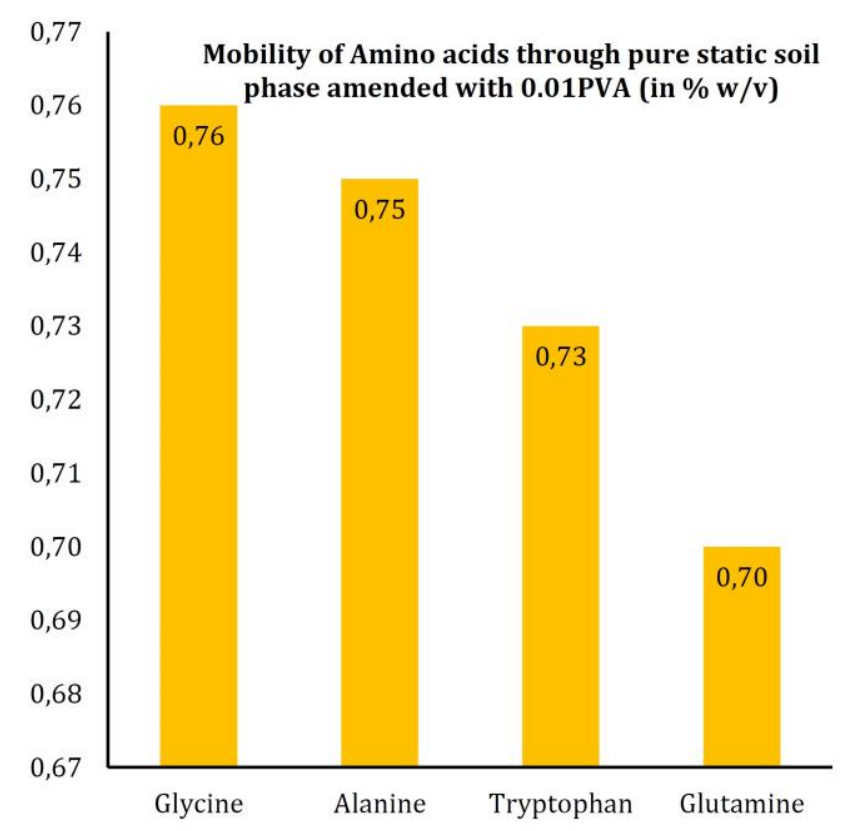

Figure 4. Mobility of amino acids through stationary soil phase amended with 0.01PVA (in \% weight divided by volume) 


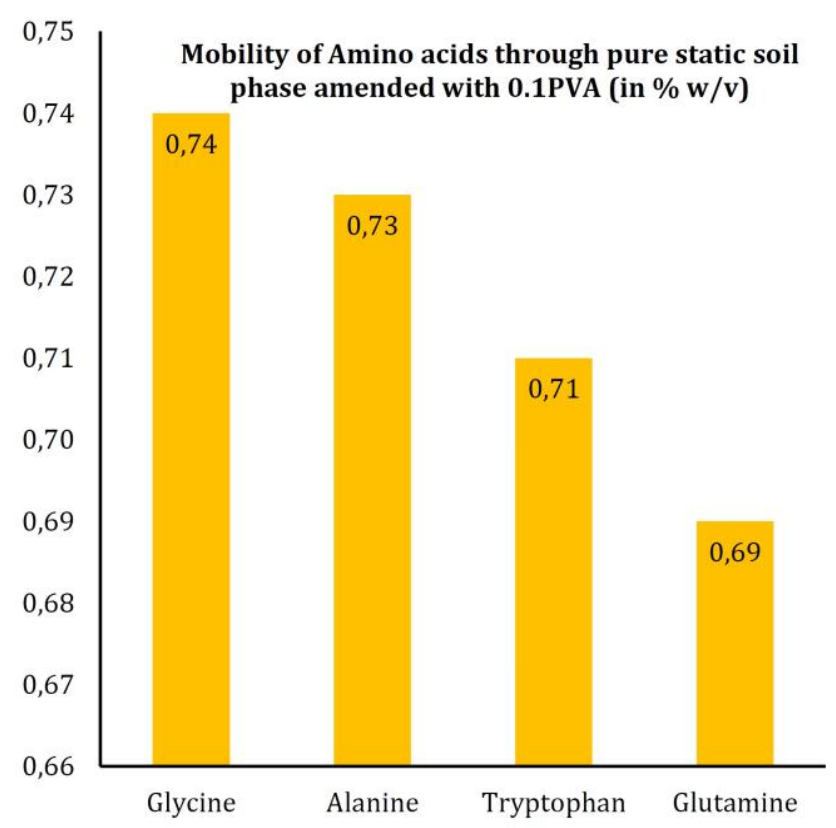

Figure 5. Mobility of amino acids through stationary soil phase amended with 0.1 PVA (in \% weight divided by volume)

\section{Effect of $\mathbf{p H}$ and Electrical Conductivity}

The $\mathrm{pH}$ and EC of soil bed with different concentration of PVA have been studied and results have been indicated in figure 6. It has been observed from the results that as the concentration of PVA increases, the value of $\mathrm{pH}$ also increases. However, $\mathrm{pH}$ and $\mathrm{EC}$ are negatively correlated as per results. It has also been observed from the result that as the concentration of PVA increases in soil bed, EC went on decreasing. This may be due to the change in the physical structure of the soil. Soil $\mathrm{pH}$ also affects physical and chemical behaviour of soil. Soil electrical conductivity is directly related to salinity. Salinity generally refers to the presence of soluble salt in the soil. Soil pH may probably affect the solubility of salts. More alkaline soil is having lower values of soluble salt. Hence low value of soil $\mathrm{pH}$ will have high soluble salt and therefore high electrical conductivity.

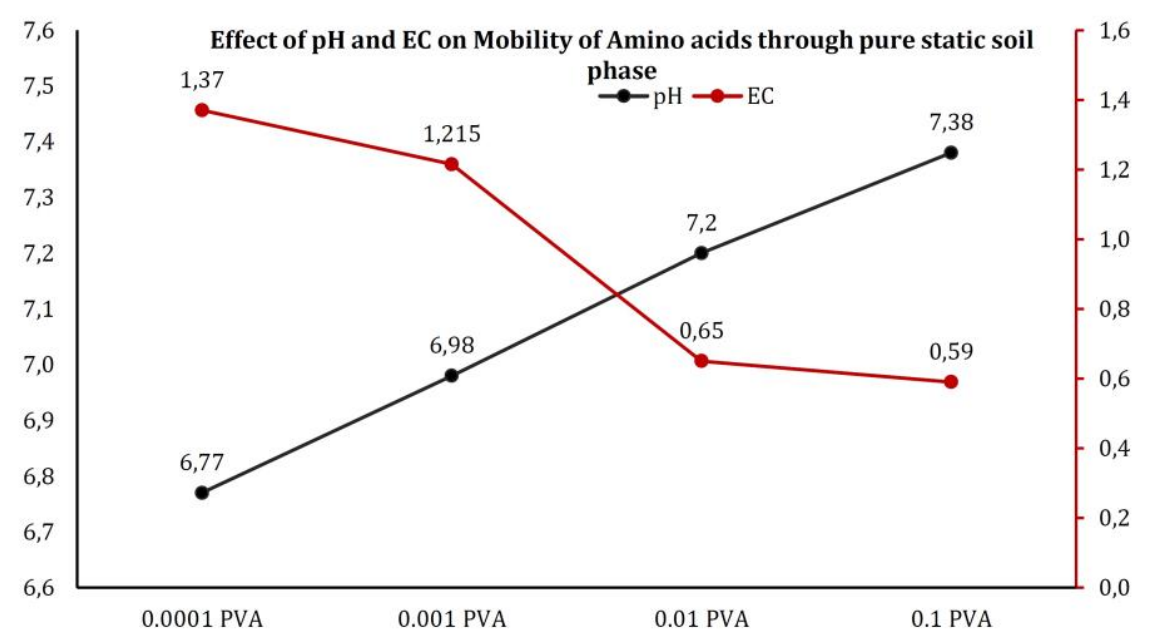

Figure 6. Effect of pH and EC on Mobility of Amino acids amended with various concentration of PVA

$(0.001 \%, 0.1 \%, 1 \%, 10 \%$ respectively)

\section{Effect of thermal activation of plate}

Soil TLC plates which dried at room temperature have been thermally activated by heating at temperature of $55-60^{\circ} \mathrm{C}$ for $30 \mathrm{~min}$ in an oven. The study was repeated using the thermally activated plates and results have been compared. It was observed that mobility of amino acids was found to be same with plates dried at room temperature as well as with thermally activated plates.

\section{Influence of particle size of soil}

Effect of soil particle size on the mobility of different amino acids was done by taking two different soil size viz; 100 mesh and 200 mesh size. The study was done under identical conditions. However, with increasing soil particle size from 100 to 200 mesh, development time for travelling of mobile phase also increases by 10 
to $15 \mathrm{~min}$ in each case. Minor reduction in $\mathrm{R}_{\mathrm{f}}$ values of amino acids were also observed. Although no significant changes were observed in $\mathrm{R}_{\mathrm{f}}$ values of amino acids. Maximum reduction was only $3 \%$ from average $R_{f}$ values. It may be because of an increase in the holding capacity of the soil and soil amended with PVA for amino acids as a result of the increased surface area of the particles.

\section{Conclusion}

The present work deals with physico-chemical properties of Aligarh soil and effectiveness of stationery soil phase and soil amended with PVA as an analytical tool to study the mobility of different amino acids. Results shows trend of transportation of amino acids through soil and soil amended with PVA. Results indicate that among the four amino acids, $R_{f}$ values were found to be maximum in case of glycine and minimum in case of glutamine through pure soil and soil amended with PVA. All amino acids namely glycine, alanine, tryptophane and glutamine are uncharged in nature but their interaction with PVA increases the adsorption site and promotes adsorption of soil particles (clay) and soil organic matter. The mobility of different amino acids decreases with high molecular masses of amino acids. It has also been concluded from the study that as the concentration of PVA increases in soil, value of $\mathrm{pH}$ also increases. However, electrical conductivity is found to be decreasing with increasing concentration of PVA. It was also observed from the study that particle size of soil does not have any significance effects on the mobility of amino acids through pure soil and soil amended with PVA. It is, therefore, understood from the results that this study will provide direction for further application in the field of Soil Thin Layer Chromatography.

\section{Acknowledgment}

The authors (S. Jabin and P. Gupta) would like to acknowledge Dr. Jamal Ahmad Khan (Department of Applied Chemistry, Faculty of Engineering \& Technology, AMU, Aligarh, India.) for providing expert guidance on procedures and experimentation.

\section{References}

Aprile, F., Lorandi, R., 2012. Evaluation of cation exchange capacity in tropical soil using different analytical methods. Journal of Agricultural Science 4(6):275-289.

Aslam, M., Kalyar, M.A., Raza, Z.A., 2018. Polyvinyl alcohol: A review of research status and use of polyvinyl alcohol based nanocomposites. Polymer Engineering and Science 58(12): 2119-2132.

Ding, B., Kim, H.Y., Lee, S.C., Shao, C.L., Lee, D.R., Park, S.J., Kwang, G.B., Choi, K.J., 2002. Preparation and characterization of a nanoscale poly(vinyl alcohol) fiber aggregate produced by an electrospinning method. Journal of Polymer Science, Part B: Polymer Physics 40(13): 1261-1268.

Jones, D.L, Shannon, D., Junvee-Furtune, T., Farrar, J.F., 2005a. Plant capture of free amino acids is maximized under high soil amino acid concentrations. Soil Biology and Biochemistry 37(1): 179-181.

Jones, D.L., Healey, J.R., Willett, V.B., Farrar, J.F., Hodge, A., 2005b. Dissolved organic nitrogen uptake by plants-an important N uptake pathway?. Soil Biology and Biochemistry. 37(3): 413-423.

Khan, J.A., Usmani, S.F., Khan, S., 2012. Effect of fly ash on the mobility of amino acids through six typical soils of Aligarh district. Journal of Pharmaceutical and Biomedical Sciences. 15(5): 1-4.

Khan, S.U., Bhardwaj, R.K., Jabin, S., 2000a. Influence of some chemical fertilizers on the mobility of trace metals through soil amended with fly ash. Pollution Research 19(2): 241-244.

Khan, S.U., Khan, J.A., Bhardwaj, R.K., Jabin, S., 2000b. Effect of some organic compounds on the mobility of some trace metals through soil amended with fly ash. Journal of the Indian Chemical Society 77(7): 326-328.

Khan, S.U., Moheman, A., 2005. Effect of some anions on the mobility of amino acids in soils by thin layer chromatography, Journal of Environmental Science and Engineerin. 47(4):310-315.

Liu, J., Wang, Y., Lu, Y., Feng, Q., Zhang, F., Qi, C., Wei, J., Kanungo. D.P., 2017. Effect of polyvinyl acetate stabilization on the swellingshrinkage properties of expansive soil. International Journal of Polymer Science Article ID 8128020.

Mitchell, J.K., Kenichi, S., 2005. Fundamentals of Soil Behavior. $3^{\text {rd }}$ Ed. John Wiley Publication, 592p.

Mohammad, A., Moheman, A., Al-Desoky, G.E., 2012. Amino acid and vitamins determination by TLC/HPTLC: review of current state. Central European Journal of Chemistry 10(3): 731-750.

Ros, G.H., Hanegraaf, M.C., Hoffland, E., van Riemsdijk, W.H., 2011. Predicting soil N mineralization: Relevance of organic matter fractions and soil properties. Soil Biology and Biochemistry 43(8): 1714-1722.

Schulten, H.R., Schnitzer, M., 1997. The chemistry of soil organic nitrogen: a review. Biology and Fertility of Soils 26(1): 1-15.

Souza, D.M., Morais, P.A.O., Matsushige, I., Rosa, L.A., 2016. Development of alternative methods or determining soil organic matter. Revista Brasileira de Ciência do Solo 40: 1-17.

Swarnakumari, S., Mohan, S., Ida, V.E., Abinaya, S., Kalaivani, S., 2019. Isolation and high-performance thin-layer chromatography analysis of conditional amino acids from the fresh leaves of alternanthera sessilis. Asian Journal of Pharmaceutical and Clinical Research. 12(2): 137-141.

Tian, D., Xie, H.Q., 2008. Influence of microemulsion conditions on the thin layer chromatographic behavior of amino acids. Journal of Liquid Chromatography and Related Technologies. 31(5):763-771.

Tian, X., Wang, K., Liu, Y., Fan, H., Wang, J., An, M. 2020. Effects of polymer materials on soil physicochemical properties and bacterial community structure under drip irrigation. Applied Soil Ecology 150. 103456. 